\title{
BIM-BASED MOBILE SYSTEM FOR FACILITY MANAGEMENT
}

\author{
Changyoon Kim, Hynsu Lim, Hongjo Kim and *Hyoungkwan Kim \\ Yonsei University \\ 50 Yonse Street \\ Seoul, Korea 120749 \\ (*Corresponding author: hyoungkwan@yonsei.ac.kr)
}




\title{
BIM-BASED MOBILE SYSTEM FOR FACILITY MANAGEMENT
}

\begin{abstract}
Technological advances in mobile systems, such as smartphones and tablet computers, provide engineers with new opportunities to enhance the current facility management processes. Equipped with powerful system processors, touch screens, and wireless communication capabilities, mobile systems enable the experience of omnipresence of facility information. Building information modeling (BIM) also enables improvements in facility management. With an advanced data structure and visualization capacity, BIM can be used in numerous applications for facility management. This study aims to incorporate the strength of mobile systems and BIM in facility management. The proposed system, which utilizes smartphone technology, allows engineers to conduct facility management functions, such as maintenance planning, inspection, and assessment, irrespective of a user's location. The integration of building information modeling in a system provides detailed visual information of the building components. A case study was conducted to verify the applicability of the mobile system in terms of the hardware functions, system design, and user interface. This proposed system, with its study results, provides a guideline as to how mobile systems can be effectively integrated with BIM for improved management of facility information.
\end{abstract}

\section{KEYWORDS}

Building Information Modeling, Facility Management, Mobile Computing

\section{INTRODUCTION}

Successful facility management requires effective management of facility data. Facility data generated through maintenance planning, inspection, and assessment should be systematically stored, transferred, and accessed. However, efficient management of facility data is not a simple task due to two important aspects. First, it is challenging to organize and store complex facility data such that they provide structured facility information for high-value decision making. It is important for facility management systems to rely on well-structured data models that can satisfy the need for effective data storage, search, and retrieval. Second, it is also challenging for facility data to be easily accessed by users in the field. The current practices require the users to come to office to obtain or record facility data through the facility management system. An ideal facility management system would provide solutions to the two aforementioned challenges.

Building information modeling (BIM) significantly improves facility management. The objectoriented concept of BIM allows each component of a facility to be handled separately, which enables a range of maintenance information, including repair costs, maintenance schedules, and product numbers, to be individually attached to a particular component. In addition, the $2 \mathrm{D}$ and $3 \mathrm{D}$ visualization capacity of BIM facilitates the identification of a problem area by a user. Combined with database technology, BIM can potentially create a powerful information system that is capable of efficiently generating and structuring facility management data.

Mobile computing technology also enables advanced facility management. Practitioners in facility management often need to take prompt action in the field. For example, when inspectors identify problems in a facility, information about the problem should be immediately input into the facility management system; however, personnel often have to return to an office to access a computer terminal before this information can be entered into the system. That way, more accurate recording of the problem can be 
stored and transferred to other users of the system in real time. Numerous advantages can materialize in facility management if mobile computing is combined with BIM. For example, inspectors can immediately examine the $2 \mathrm{D}$ or $3 \mathrm{D}$ drawings of a problem area to understand the facility and identify areas that require thorough examination. They can also instantly extract a variety of information, such as information about part manufacturers and equipment installation contractors. Motivated by the combined strength of BIM and mobile computing, this study proposes a BIM-based mobile system for facility management.

\section{LITERATURE REVIEW}

Previous studies in the area of facility management can be roughly categorized into three classes: process development, information systems, and BIM- or mobile computing-based systems. Ottoman et al. (1999) identified 18 estimation models for facility maintenance and repair. Comparison of the 18 models in terms of a theoretical estimating approach provided a guideline for facility managers to select a proper estimation method. Yu et al. (2000) presented a framework to develop data models for facility management and computer-integrated facility management systems. They proposed new data models (Facility Management Classes (FMC)) and argued that FMC are better suited for facility management than Industry Foundation Classes. Hassanain et al. (2003) presented an asset maintenance process in the form of an IDEF0 model. The process demonstrated required activities and a methodology of communication between activities.

Wang and Xie (2002) developed a facility management system that integrated open control networks with the Internet. Technologies such as an embedded Web server, a PC Web server, and a Distributed Component Object Model were used and tested for system development. Song et al. (2002) studied the feasibility of web technology to deliver building information for facility operations. They proposed just-in-time documentation to demonstrate how design and construction information can be reused for facility operations. Ergen et al. (2007) investigated how radio frequency identification (RFID) technology can improve current facility management processes. They showed that RFID can be used to improve routine maintenance and inspection activities.

Park et al. (2011) presented a statistical analysis of the way engineers perceive the effectiveness of BIM for life cycle facility management. An importance-performance analysis was conducted, and a questionnaire-based survey was administered to identify the areas in which BIM has significant potential for enhancing existing practices. Becerik-Gerber et al. (2012) explored how BIM can be a beneficial tool for supplementing facility management practices. Interactions between BIM and facility management were defined by illustrating application areas and data requirements for BIM-based facility management. Jiao et al. (2012) presented a self-organized business social network service (BSNS) application for the gathering and sharing of lifecycle construction data. They integrated BSNS and BIM models for unified lifecycle data management. Lucas et al. (2013) proposed an object-oriented product model for the development of an information management framework for a healthcare facility. The framework consisted of a BIM-based system for easy recall of facility information during operation and maintenance phases.

This review of previous studies reveals the history and progress of facility management. Although these studies advanced facility management practices, there remains a distinct need for improvements in the field. They also indicate that not many studies have been devoted to developing a system that combines BIM and mobile computing for facility management. Motivated by the successes and weaknesses of previous studies, this study proposes a BIM-based mobile system for facility management.

\section{FACILITY MANAGEMENT PROCESS BASED ON BIM AND MOBILE COMPUTING}

Figure 1 illustrates the proposed facility management (FM) process based on the combination of BIM and mobile computing. First, IDEF0 models were deployed to define a BIM-based facility management process. The BIM-based process was composed of five steps: BIM-based database development, inspection, assessment, repair, and post-repair management. IDEF0 models were developed for the entire maintenance process and for each specific step. They were then validated by a focus group interview of seven experts in the field. The models were subsequently improved and condensed by considering the mobile computing component for developing the facility management process, as shown in 
Figure 1. Note that certain initial efforts are required to develop a 3D BIM model and to transform it into a BIM-based mobile database with schedule, inspection, assessment, repair, and post-repair status data inputs.

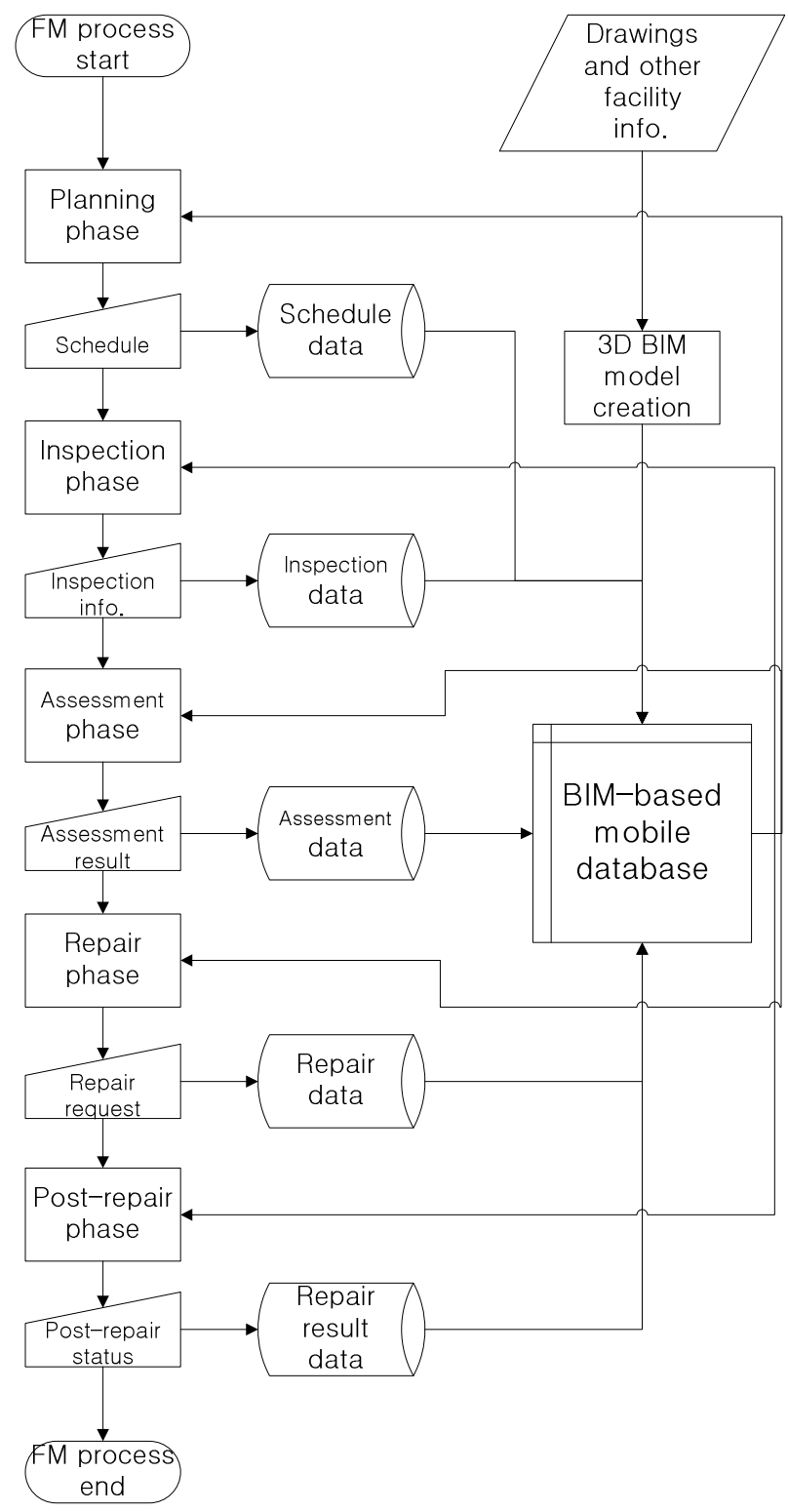

Figure 1. Facility management process based on BIM and mobile computing

\section{BIM-BASED MOBILE SYSTEM FOR FACILITY MANAGEMENT}

Based on the process defined in the previous section, the BIM-based mobile system was developed for facility management. Object-C was used as the programming language in an Xcode environment for the development of the iPhone 3GS application. AutoCAD Inventor Publisher Mobile Viewer was used to visualize the 3D BIM models. SQLite was employed for the maintenance manual database component. The system was composed of five distinctive modules: planning, inspection, assessment, repair, and 3D visualization. The 3D models for the system were first generated on the Autodesk Revit Architecture Suite platform. Then, the file produced in the Revit was converted into the 
Inventor Publisher Mobile Viewer file to have the extension of 'ipm' and appropriate size (approximately 1.5 MB) for the smartphone. The planning module allowed the user to generate schedule information, such as name, location, date, and work description, according to a predefined classification rule. The inspection module presented a list of items for inspection and allowed the user to comment on each item after inspection; it also provided a search function for 2D drawings. The assessment module enabled a decision maker to approve repair requests; the inspector's opinion, which was recorded in the inspection phase, was retrievable from the database for the approval process. The repair module facilitated identification of the problem area and the development of actions; information regarding repair time and price could be input into this module. Figures $2 \mathrm{a}, 2 \mathrm{~b}$, and $2 \mathrm{c}$ illustrate the planning, inspection, and $3 \mathrm{D}$ visualization modules, respectively.

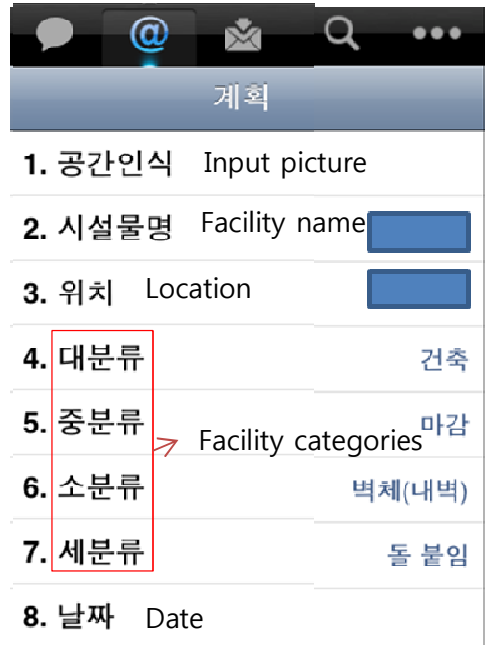

(a) Planning module

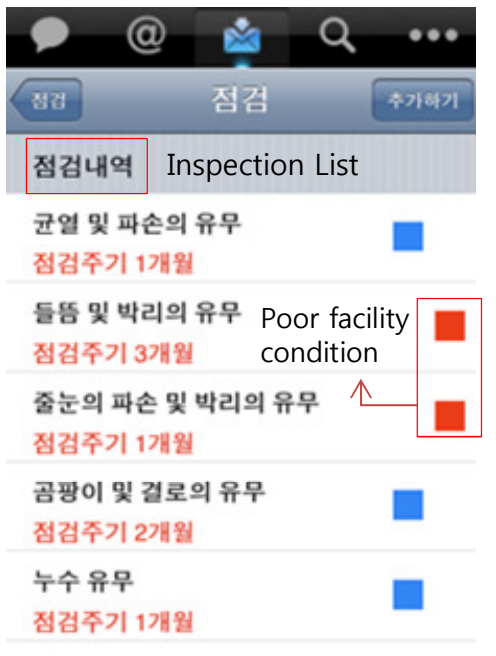

(b) Inspection module

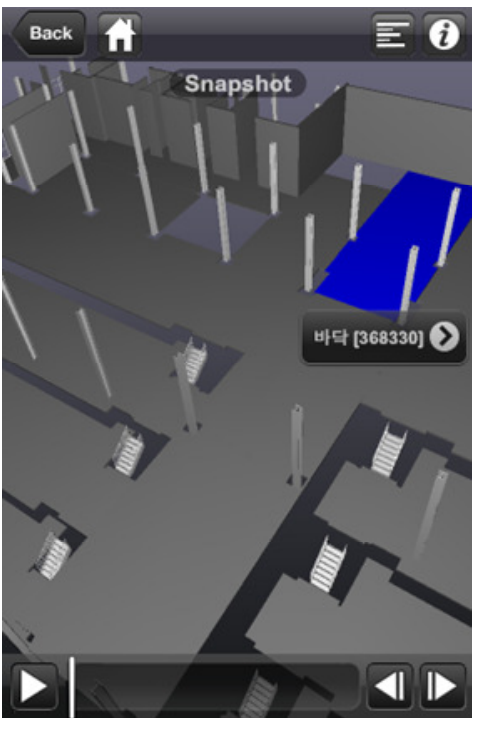

(c) 3D visualization module

Figure 2. BIM-based mobile system for facility management

\section{VERIFICATION}

A case study, involving a university library building, was conducted to verify the applicability of the mobile BIM-based facility management system. The building chosen for the study was a Samsung library building in the Shinchon campus of Yonsei University. The building contained three basement floors and six upper floors, with a total area of $33,000 \mathrm{~m}^{2}$. A total of 60 hours was required to produce 3D CAD models for the BIM-based facility management system. Four specific components of the building were selected for the case study: wall finishing material, floor finishing material, elevators, and fire extinguishers. Five actual maintenance personnel were requested to use the system for evaluation of the aforementioned four specific components of the buildings. After experiencing all modules of the system as part of their regular maintenance practices, they completed a questionnaire-based survey to express their opinions. The survey questions explored the issues of hardware, user interface, and maintenance functions. The hardware issue included screen size and processing time of facility management. User interface issue included various design factors such as text size, level of detail of the 3D model, and shape of the icons. Maintenance functions were also assessed by evaluating the applicability of the mobile facility management processes. Although some complaints about certain issues, such as small screen size, were expressed, the personnel primarily expressed positive opinions about the system. Their results indicated that the facility management system has the potential to advance the existing practices of facility management. 


\section{CONCLUSIONS}

Motivated by the power of BIM and mobile computing, this paper presented a BIM-based mobile system for facility management. The system was composed of five distinctive modules: planning, inspection, assessment, repair, and 3D visualization. For its verification, the system was implemented on the platforms of the iPhone 3GS and the AutoCAD Inventor Publisher Mobile Viewer. The results of the case study demonstrated that the maintenance personnel were primarily satisfied with the performance of the system, which indicated a strong potential for the system to improve traditional facility management processes.

Future studies are required to fully demonstrate this system to the construction industry. User interface issues, such as small screen size, remain problematic. The completion of further studies for the development of a more comprehensive and user-friendly system will enable industry practitioners to adopt this emerging technology for actual field practice. A comparison study between the current facility management and the facility management using the smartphone is also required to analyze the time and cost efficiency of the BIM-based mobile facility management system.

\section{ACKNOWLEDGMENT}

This work was supported by grants (2010-0014365 and 2011-0030841) from the National Research Foundation and Ministry of Education, Science, and Technology of Korea.

\section{REFERENCES}

Becerik-Gerber, B., Jazizadeh, F., Li, N., \& Calis, G. (2012). Application Areas and Data Requirements for BIM-Enabled Facilities Management. Journal of Construction Engineering and Management, 138, 431-442.

Ergen, E., Akinci, B., East, B., \& Kirby, J. (2007). Tracking Components and Maintenance History within a Facility Utilizing Radio Frequency Identification Technology. Journal of Computing in Civil Engineering, 21, 11-20.

Hassanain, M. A., Froese, T. M, \& Vanier, D. J. (2003). Framework Model for Asset Maintenance Management. Journal of Performance of Constructed Facilities, 17, 51-64.

Jiao, Y., Wang, Y., Zhang, S., Li, Y., Yang, B., \& Yuan, L. (2012). A cloud approach to unified lifecycle data management in architecture, engineering, construction and facilities management: Integrating BIMs and SNS. Advanced Engineering Informatics, in-press.

Lucas, J., Bulbul, T., \& Thabet, W. (2013). An object-oriented model to support healthcare facility information management. Automation in Construction, 31, 281-291.

Ottoman, G. R., Nixon, W. B., \& Lofgren, S. T. (1999). Budgeting for facility Maintenance and Repair. 1: Methods and Models. Journal of Management in Engineering, 15, 71-83.

Park, J., Kim, B., Kim, C., \& Kim, H. (2011). 3D/4D CAD Applicability for Life-Cycle Facility Management. Journal of Computing in Civil Engineering, 25, 129-138.

Song, Y., Clayton, M. J., \& Johnson, R. E. (2002) Anticipating reuse: documenting buildings for operations using web technology. Automation in Construction, 11, 185-197.

Wang, S., \& Xie, J. (2002). Integrating Building Management System and facilities management on the Internet. Automation in Construction, 11, 707-715.

Yu, K., Froese, T., \& Grobler, F. (2000). A development framework for data models for computerintegrated facilities management. Automation in Construction, 9, 145-167. 